\title{
Incorporating Technological Change in Diffusion Models
}

\author{
Mary K. Knudson
}

\begin{abstract}
The theoretical and empirical implications of a static and dynamic logistic diffusion model are compared. The dynamic model relaxes some assumptions of the static model by allowing for a flexible adoption ceiling, for changes in the technology, and for disadoption. Both models were used to estimate the diffusion of semi-dwarf wheat varieties in the United States. The dynamic model provides a better fit to the data and provides additional insights into the economic determinants of adoption. In particular, the importance of technological change in other areas (here, in fertilizer) on the diffusion path of an innovation was shown.
\end{abstract}

Key words: diffusion, semi-dwarf wheat varieties, technological change.

In constructing diffision models, economists have faced a difficult trade-off. A host of probabilistic frameworks (such as the logistic, probit, and Gompertz; see Griliches 1957, Dixon) permit straightforward estimation of the diffusion trend of an innovation. Ease of estimation, however, comes at the cost of exogenously determined (and often theoretically unjustified) constraints on the rate of adoption and on the point at which the greatest rate of adoption occurs. For example, the logistic model requires the greatest rate of adoption to occur when $50 \%$ of the population has adopted the innovation. (For further criticisms of the static diffusion framework, see Mahejan and Peterson 1985.)

A number of the theoretically troublesome assumptions of the static diffusion model have been relaxed by Metcalfe and Gibbons. They present a dynamic diffusion framework which allows the inflection point of the diffusion curve to arise endogenously from the specifications of the model. Their model is of further interest because it depicts explicitly the interactive relationship between research and development and diffusion/adoption. Unfortunately, the data requirements for estimation of the Metcalfe and

Mary K. Knudson is a visiting assistant professor, The Institute of Public Policy Studies, University of Michigan.

Work on this paper was supported by the Resources and Technology Division of the U.S. Department of Agriculture, Economic Research Service. The views expressed in this paper are the author's and do not necessarily reflect views or policies in this paper of the Economic Research Service.

The author would like to acknowledge Wiktor Adamowicz, Willis Peterson, Vern Ruttan, three anonymous referees, and, especially, Douglas Dion for their helpful suggestions. Remaining errors are the author's.
Gibbons model are onerous. For example, input costs, including research costs, are required. However, firms are typically unwilling to release such input data.

This paper presents a method for overcoming data limitations in estimating dynamic diffusion models while incorporating additional variables to explain technological change. This methodology has potential application to a variety of diffusion cases, including the adoption of herbicide-resistant crop varieties and low-input agricultural practices. The technique is applied to estimating the diffusion of semi-dwarf wheat varieties (SDWVs). SDWVs are an important yield-increasing biological innovation which has substantially altered the agricultural practices of wheat growers in the United States. To emphasize the value of the dynamic approach, results from the dynamic model will be compared to estimates from a more traditional static diffusion model. As shall be shown, the dynamic model not only provides better estimates of the diffusion of semi-dwarf wheat, but also allows the researcher to determine the impact on the diffusion process of a variety of factors not incorporated within the traditional static model.

This paper is organized as follows. The first section presents the traditional static diffusion model, followed by Metcalfe and Gibbon's generalization to the dynamic case. The third section indicates how market data can be used to yield estimates for dynamic diffusion trends. The fourth section presents the results of a generalized least squares estimation of the traditional static diffusion model and of a dynamic diffu- 
sion model for semi-dwarf wheat. Finally, some concluding remarks are made.

\section{A Basic Diffusion Model}

The basic diffusion process contains four components: the innovation, the social system in which the innovation is being adopted, channels of communication, and time (Metcalfe and Gibbons, Mahajan and Peterson 1985, Bayer and Melone). The innovation component represents the new product being diffused. Inherent in the new product are characteristics that affect its diffusion. ${ }^{\prime}$ A social system is comprised of individuals, organizations, or agencies and their adopting strategies. How a total group of adopters transmits information about an innovation depends on how heterogenous and cohesive a group of adopters is. The ways that adopters pass on information about an innovatioon are the channels of communication. Finally, time is the period over which a social system adopts an innovation. Because these four components are present in every diffusion process, any realistic model of diffusion must incorporate them.

In addition, six basic assumptions underlie the diffusion model (See, for example, Mahajan and Peterson 1985.): (Al) The adoption decision is binary. An individual adopts or does not adopt. (A2) A fixed, finite ceiling $N^{M}$ exists. (A3) The coefficient of diffusion (defined below) is fixed over time. (A4) The innovation is not modified once introduced, and its diffusion is independent from the diffusion of other innovations. (A5) One adoption is permitted per adopting unit and this decision cannot be rescinded. (A6) A social system's geographical boundaries stay constant over a diffusion process.

Incorporating the four components, and assuming (A1)-(A6), the basic diffusion model takes the following functional form (This discussion follows the notation found in Mahajan and Peterson 1985.):

$$
d N(t) / d t=g(t)\left[N^{M}-N(t)\right],
$$

where $d N(t) / d t$ is the rate of diffusion at time

\footnotetext{
'Economists sometimes classify innovations into process and product. A process innovation is an input to a production process. A product innovation is an end product. Generally, product innovations are easier to assess than process innovations because their performance can be measured directly. However, many innovations fall into both categories. That is, one firm's product innovation, say a seed variety, may become a process innovation for another firm. For the purposes of this paper, what category the innovation falls into does not matter as long as it is measurable. For simplicity, product is used.
}

$t$, (or, more simply, changes in adoption over time) where $t$ begins at $t_{0} ; g(t)$ is the coefficient of diffusion. This coefficient indicates how fast and to what degree adoption occurs. The higher the coefficient, the earlier and greater degree of adoption of an innovation.

The cumulative number of adopters at time $t$ is $N(t)$, or

$$
N(t)=\int_{t_{0}}^{t} n(t) d t,
$$

and $n(t)$ is the number of adopters per time period $t ; N^{M}$ is the maximum number of adopters in a social system over time $t$. The number of potential adopters left at time $t$ is $N^{M}-N(t)$.

While it is clear how innovation and time fit into model (1), the entry of social system and channels of communication are not directly apparent. Their effect is found in the diffusion coefficient, $g(t)$. The specific form of $g(t)$ reflects the influence of the social system and the channels of communication on the diffusion process. For example, when a social system is heterogenous, fragmented, and lacks communication, $g(t)=b$, where $b$ represents the natural rate of diffusion, i.e., that rate which occurs without any other influence. The resulting diffusion model, $d N(t) / d t=b\left[N^{M}-N(t)\right]$, is called the external influence model. However, when the social system is homogenous and communicative, $g(t)=b N(t)$, where $b$ still is the natural rate of adoption and $N(t)$ is the impact adopters have on the remaining number of nonadopters, $N^{M}-N(t)$. The resulting diffusion model,

$$
d N(t) / d t=b N(t)\left(N^{M}-N(t)\right),
$$

is known both as an internal influence model and as the logistic model; it was used to estimate the diffusion of hybrid corn in Griliches' (1957) seminal piece.

The logistic model imposes an S-shaped, symmetric diffusion trend with a maximum diffusion rate occurring when $50 \%$ of the potential cumulative adopters have adopted. ${ }^{2}$ It is based on the premise that diffusion occurs through interpersonal contacts among a group of homogenous adopters (Mansfield). But not all diffusion models require symmetry around a $50 \%$ inflection point. For example, the Gompertz model, $d N(t) / d t=b N(t)\left(\log N^{M}-N(t)\right)$, im-

\footnotetext{
${ }^{2}$ For proofs of the logistic model's inflection point and its symmetric diffusion trend, see Mahajan and Peterson 1985, pp. 27-
} 28. 
poses an asymmetric trend with the maximum diffusion rate occurring when $37 \%$ of the potential cumulative adopters have adopted. ${ }^{3}$ The assumption here is that although adopters are homogenous, early adopters are relatively more cohesive than middle and late adopters; therefore, they adopt at a faster pace. Dixon used the Gompertz and traditional logistic models to reestimate the diffusion of hybrid corn. He found the Gompertz model was a more accurate measure of hybrid corn diffusion.

Because farmers within a region or country often have similar production practices (homogenous) and communicate well with each other (cohesive), it makes sense to use a traditional logistic model to estimate the diffusion of an agricultural innovation (Mahajan and Peterson 1985). Hence, in this paper, the traditional logistic model is uscd to estimate the diffusion of semidwarf wheat. Because this model will be compared to a dynamic model, the traditional logistic model will hereafter be called the static logistic model.

\section{Dynamic Diffusion Models}

Static diffusion models work best when the adoption process being modeled satisfies the assumptions (A1)-(A6) listed above, and when the inflection point for the adoption trend occurs at the same point as the inflection point for the functional forms listed above. For many applications, however, static diffusion models are open to two objections. First, in many cases there will be no rationale ex ante for assuming that diffusion follows a particular trend. Second, the assumption of a fixed ceiling on the adopting population is unrealistic in most economic contexts. For example, the potential number of adopters of a biological innovation will vary depending upon the availability of the innovation,

\footnotetext{
${ }^{3}$ A Gompertz model takes the form, $d N(t) / d t=b N(t)\left[\log N^{M}\right.$ $-N(t)$ ], where $b$, and $N(t)$ and $N^{M}$ are as defined in the text. The following is a proof that the Gompertz model has a maximum diffusion rate when $37 \%$ of the potential adopters adopt and is asymmetric.

Let $N$ be expressed as a fraction of $N^{M}$, so $d N(t) / d t=b N(t)$ $\left(\log N^{M}-\log N(t)\right)$ becomes $(d N(t) / d t)\left(1 / N^{M}\right)=b\left(N(t) / N^{M}\right)\left(\log \left(N^{M}\right)\right.$ $\left.N^{M}\right)-\log \left(N(t) / N^{M}\right)$ ). Let $F(t)=N(t) / N^{M}$, and ignore the subscript $t$ for convenience; $(d N(t) / d t)\left(1 / N^{M}\right)$ becomes $d F / d t=b F(\log 1-$ $\log F)=b F(\log (1 / F))$.

To find the maximum growth rate, $F^{M}$, differentiate with respect to $F ;(d F / d t) / d F=b \log (1 / F)-b F^{M}\left(1 / F^{M}\right)=0$; rearranging, $b \log \left(1 / F^{M}\right)=b \log \left(1 / F^{M}\right)=1$ or $F^{M}=0.37$. The maximum dif fusion rate occurs when $37 \%$ of the potential adopters have adopted and is skewed to the left, making the diffusion trend asymmetric.
}

which itself is a result of the profit-maximizing efforts of firms.

Models are needed that allow more flexibility with regard to the inflection and symmetry points (Mahajan and Peterson 1985, Knudson). Dynamic models allow the determinants of diffusion to change every time period, and, hence, may more accurately measure the rate of adoption than a static model. For example, as the real price of an innovation decreases and stabilizes, an innovation becomes more attractive and is adopted more rapidly. A dynamic model could capture this change; a static model could not.

In addition, as a result of its flexible form, dynamic models can include more variables that affect diffusion and therefore measure more directly these factors' impact. For instance, the impact of such factors as prices or profit can be included in the diffusion model. Conceptually, then, a diffusion trend becomes an envelope of individual, distinct diffusion trends that a set of distinct variables define in each time period (Chow; Mahajan and Peterson 1978, 1985; Metcalfe and Gibbons; Stoneman).

Studies by Mahajan and Peterson (1978) and by Metcalfe and Gibbons were used to develop such a dynamic model. In particular, the Mahajan and Peterson study established an approach for modifying static models. They began by relaxing assumption (A2), which states that $N^{M}$ is fixed and finite, claiming that (A2) is inconsistent with theory and practice. To make $N^{M}$ dynamic, Mahajan and Peterson defined $N^{M}$ as a function $f(s(t))$, where $s(t)$ is a vector of " (potentially) all relevant exogenous and endogenous factors, both controllable and uncontrollable, affecting $N^{M}(t)^{n}$ (p. 1590). How well $f(s(t))$ represents $N^{M}(t)$ depends on the accuracy in estimating $s(t)$ and the closeness of $s(t)$ or $f(s(t))$ in measuring $N^{M}(t)$. Hence, by redefining $s(t)$ or $f(s(t))$, this approach can be tailored to measure the diffusion of distinctly different innovations.

Metcalfe and Gibbons relaxed assumptions (A2)-(A4) to build a dynamic model that is "based upon the simultaneous development of market demand and the accumulation of productive capacity" (p. 5). They take a static logistic model and make $N^{M}(t)$ a function of a simple market demand equation, $c-a p(t)$, where $p(t)$ is prices paid by the consumer at time $t$. Their $p(t)$ is determined endogenously within an industry; hence, it represents the equilibrium price (reflecting the growth rate capacity and profit rate of a firm). Their model takes the final form; 


$$
d N(t) / d t=g(t)\left[N^{M}(t)-N(t)\right],
$$

where $g(t)$ is a function of technology, the natural rate of diffusion, and the capacity for a firm to invest in research and development.

The approach utilized by Metcalfe and Gibbons relaxes many of the basic assumptions of the diffusion model listed in the preceding section. By allowing the adoption ceiling to be a function of time (as well as technology and the parameters of equilibrium demand and supply), the assumption of a fixed adoption ceiling (A2) is relaxed. All three components $g(t)$ listed above may change every time period; hence (A3) (the assumption that the diffusion coefficient is fixed) is relaxed. (A4) is relaxed as the model allows directly for improvements in the innovation and for improvements in the means of producing the innovation. (For further details of model (3); see Metcalfe and Gibbons and Metcalfe.)

\section{Modeling the Diffusion of Semi-Dwarf Wheat}

Metcalfe and Gibbons present their model as a means of incorporating the full effects of the invention side in the diffusion process. Unfortunately, the cost data required for the profit rate equation are virtually impossible to obtain. Similarly, revenue for a research project is difficult to obtain, and as a result one cannot estimate marginal revenue to approximate marginal cost. Furthermore, not many proxies for research costs are available. The Metcalfe and Gibbons model, while theoretically appealing, is difficult to estimate empirically.

A model overcoming these data limitations was developed to estimate the diffusion of semi-dwarf wheat varieties (SDWV) across the U.S. Let the maximum number of adopters be a function of a wheat supply function, $N^{M}(t)=f(s(t))=y(t)$, where $y$ is the supply of wheat from semi-dwarf wheat seeds that farmers produce in time $t$. More specifically,

$$
\begin{aligned}
y(t)= & f(p r(t), p p(t), p f(t)) \\
= & c+a^{1} p r(t-1)+a^{2} p p(t-1) \\
& +a^{3} p f(t-1),
\end{aligned}
$$

where $\operatorname{pr}(t-1)$ is the price farmers receive for a bushel of grain in year $t-1, p p(t-1)$ is the price paid for SDWV seed in time $t-1$, and $p f(t-1)$ is the price paid for fertilizer in time $t-1$.

Two factors stand out in this functional form (3). First, the price variables are lagged one year.
Because a substantial lag exists between the time when production decisions are made to when production ends, price variables are often lagged. In this case, the hypothesis that a producer's expectation of prices is based on relatively recent experience is used (Tomek and Robinson). Second, the price variables are not deflated by a common deflator. Instead, the price variable that would have been the deflector is represented as a separate variable. In this case, the effect of fertilizer prices is measured.

Measuring the impact of fertilizer prices as an independent variable makes sense for two reasons. First, for the innovation studied here (SDWV), high yields were obtained through the use of heavier fertilizer application. Therefore, the use of fertilizer as a deflator may bias the regression results (Tomek and Robinson). Second, because fertilizer prices fluctuated greatly in the 1970s, separating prices received and other input prices from fertilizer prices allows for more accurate measurements of the impact of these variables on supply (Meilke).

The main difference between this model of diffusion and that of Metcalfe and Gibbons is that prices are now exogenous. However, because the supply function depends on factors that affect a farmer's decision to adopt, a supply function still connects the stages of research and development and diffusion/adoption. For example, suppose high fertilizer prices deter the adoption of SDWV. A firm may use this information to develop SDWVs that are less dependent on fertilizer. Furthermore, as prices favor a particular production process, such as SDWV and increased fertilizer use, farm producers may use these inputs to utilize a profitable opportunity (Schumpeter). Work by Peterson, and Timmer and Falcon show for various commodities that as the real price of the agricultural product increases, its supply also increases. Hence, a supply function similar to that found in equation (4) also captures the ceiling of SDWV adoption. ${ }^{4}$

Substituting (4) for $N^{M}$ in equation (1) yields

$$
\begin{aligned}
& d N(t) / d t=b N(t)\left(c+a^{1} p r(t-1)\right. \\
& \left.\quad+a^{2} p p(t-1)+a^{3} p f(t-1)-N(t)\right),
\end{aligned}
$$

where $d N(t) / d t$ is the rate of diffusion in time $t, N(t)$ is the number of adopters in time $t, b$ is the natural rate of adoption, and $c, a^{1} a^{2}, a^{3}, \operatorname{pr}(t$

\footnotetext{
${ }^{4}$ The demand elasticity is assumed not equal to zero since in that case firms would not respond to the lowered price of the innovation. Therefore, technological change would have no effect on the firm.
} 
- 1), $p p(t-1)$, and $p f(t-1)$ are defined above. In equation (5), as in the Mahajan and Peterson model, the maximum number of adopters does not remain fixed over time; therefore, (A2) is relaxed. Similar to the Metcalfe and Gibbons model, the innovation is allowed to change over the diffusion process through the supply function found in equation (4); hence, (A4) is relaxed.

\section{Estimating the Diffusion of SDWV}

The parameters for the static logistic model (2) and the dynamic logistic model (5) are estimated by rewriting each equation in its discrete analogue form and then applying generalized least squares (GLS) (Mahajan and Peterson 1985, Bass, Chow, Bayer and Melone, White).$^{5}$ In terms of its discrete analogue form, $d N(t) / d t=$ $N(t)-N(t-1)$. Substituting the discrete analogue form into the static logistic model (2), and multiplying the right-hand side of (2) out, (2) becomes

$$
N(t)-N(t-1)=\left(b N^{M}\right) N(t)-b N(t)^{2},
$$

where $b N^{M}=A,-b=E$, and $N(t)$ and $N(t)^{2}$ are the same as they were [in (2)]. Equation (6) becomes by substitution,

$$
N(t)-N(t-1)=A N(t)+E N(t)^{2} .
$$

Doing the same for the dynamic logistic model, equation (5) becomes

$$
\begin{gathered}
N(t)-N(t-1)=(b c) N(t) \\
+\left(b a^{1}\right) N(t) p r(t-1)+\left(b a^{2}\right) N(t) p p(t-1) \\
+\left(b a^{3}\right) N\left(p f(t-1)-(b) N(t)^{2} .\right.
\end{gathered}
$$

Let $A=b c, B=b a^{1}, C=b a^{2}, D=b a^{3}$, and $E=-b$, and substitute, $A, B, C, D$, and $E$ for these terms in (8). Now, (8) becomes

$$
\begin{array}{r}
\quad N(t)-N(t-1)=A N(t)+B N(t) p r(t-1) \\
+C N(t) p p(t-1)+D N(t) p f(t-1)+E N(t)^{2} .
\end{array}
$$

One can now apply GLS to both equations (7) and (9).

For both models, the $A$ coefficient is expected to be positive and the $E$ coefficient negative. The greater the increase in the number of adopters, $N(t)$, between two time periods, the greater the

\footnotetext{
${ }^{5}$ The Goldfeld-Quandt test for heteroskedasticity was statistically significant and was corrected following the methodology of White.
}

diffusion rate, $N(t)-N(t-1)$. However, as the number of adopters increases, the number of potential adopters decreases. Adoption continues to increase but at a decreasing rate.

For the dynamic logistic model, a positive $B$ coefficient is expected and negative $C$ and $D$ coefficients are expected. Producers supply more of a commodity as its real market price increases. Hence, as prices increase, so does adoption and the diffusion rate. However, as an input price decreases, assuming everything else remains constant, the profitability of using that input increases, causing its adoption to increase.

\section{Variables Used}

Both the static and dynamic logistic models use the variable $N(t)$. In addition, the dynamic model also uses the variables $p r(t-1), p p(t-1)$, and $p f(t-1) . N(t)$ is measured by the percentage of total wheat land planted to SDWV's. This measure is a flexible variable, capable of capturing disadoption trends. This allows one to take advantage of relaxing assumption (A5).

An alternative measure of $N(t)$ is the area of land planted with SDWV's. One advantage of using the relative measure is to maintain consistency with other studies that measured the diffusion of a new crop variety. Griliches (1957) and Dixon used percentage of corn land planted to hybrid corn to measure hybrid corn adoption. A second justification for using the relative measure is that this study addresses the extent to which wheat farmers use SDWVs as opposed to traditional varieties. Because the only commercial alternative for wheat farmers is either the traditional or the SDW option, the relative proportion of wheat land going to SDW allows one to track the adoption of SDWV over traditional varieties within the adoption population of interest, i.e., wheat farmers. By contrast, using the absolute measure gives no insight into the adopting behavior of wheat farmers because increases in the total land planted with SDWVs need not reflect displacement of the more traditional varieties. ${ }^{6}$

Data on the percent of SDWV acreage relative to total wheat acreage are collected from a

\footnotetext{
${ }^{6}$ As a check, the model was rerun using the absolute acreage measure. The results were confusing. For example, the coefficients for $N(t)$ imply that the adoption occurred first in regions where the SDWV technology appeared last and conflicts with evidence (such as the data from the Wheat Marketing Survey) that shows otherwise. This result may reflect the erratic wheat acreages during the $1960 \mathrm{~s}$ and $1970 \mathrm{~s}$
} 
wheat marketing survey by U.S. Department of Agriculture (USDA) every five years. These data are aggregated so the unit of analysis is on a per state basis. The survey is run across forty-two states. Data on SDWV acreage allotment are available for forty-one of these states. Florida is excluded because of lack of data for many years on their wheat plantings.

The survey years for which SDWV data are available are (a) 1959, 1964, 1969, 1974, 1979, and 1984 for Idaho, Montana, Nevada, Oregon, and Washington; and (b) 1964, 1969, 1974, 1979, and 1984 for the remaining thirty-six states.

The three price variables in the model $(\mathrm{Pr}$, $P p$, and $P f)$ are measured as follows: $P r$, expected wheat prices received, is set equal to the average annual price received per bushel of wheat. $(N(t-1)$ refers to the preceding wheat survey year. However, the price variables are lagged only one year.) The price received "allows for unredeemed loans and government purchases values at the average loan and purchase rate" (USDA ERS, p. 24). Expected prices paid for seed, $P p$, equals the average annual price paid for seed. The USDA publishes seasonal average wheat price data. Finally, $P f$, expected prices paid for fertilizer, is measured by total plant nutrient expenditures (million dollars) $\left(P f^{*} Q f\right.$, where $P f$ is price of plant nutrients and $Q f$ is quantity of plant nutrients) divided by the quantity of plant nutrients consumed on the national level (1,000 tons), i.e., $P f^{*} Q f / Q f=P f$. This price accounts for technological improvements in fertilizer. As improvements occur, a unit of fertilizer will produce more nutrients, hence, reducing the real price of fertilizer. Because prices using plant nutrients are adjusted for quality and USDA fertilizer prices are not, USDA fertilizer prices are biased upwards. Therefore, this study used this measure $(P f * Q f /$ $P f$ ) of fertilizer prices.
Table 2. Characteristics for States within Each Group

\begin{tabular}{ll} 
Group & Wheat Market Class \\
\hline G1 & White \\
G2 & Hard Red Spring \\
G3 & Hard Red Winter \\
G4 & Soft Red Winter \\
G5 & Soft Red Winter \\
\hline
\end{tabular}

\section{Cross-Sectional and Time-Series Data}

Because of the lack of time-series data on a per state basis and the abundance of cross-sectional data, equations (7) and (9) were estimated using cross-sectional and time-series data. The level of analysis using cross-sectional and time-series data is the individual as opposed to a time point. For this study, the movement of SDWV adoption in one region will be described relative to its movement in another region. The advantage is that all adopters' behavior will be directly comparable.

Equations (7) and (9) must be reformulated for use in cross-sectional and time-series analysis using a slope dummy variable framework. The forty-one states are divided into five groups based on their location and similarity in wheat and growing conditions. See tables 1 and 2 for a listing of the groups and their characteristics.

A base group was selected to provide a means of comparing SDWV diffusion rates between regions. The other groups were formulated using dummy variables. The model measures the diffusion of SDWV for the base group and how the other groups differ directly from the base group. Therefore, the base group must be different enough from the rest of the groups so that statistical differences between groups can be picked up. In this study, a good base group would

Table 1. State Groups

\begin{tabular}{lllll}
\hline $\begin{array}{l}\text { Group One (G1) } \\
\text { (West) }\end{array}$ & $\begin{array}{l}\text { Group Two (G2) } \\
\text { (Upper Midwest) }\end{array}$ & $\begin{array}{c}\text { Group Three (G3) } \\
\text { (Plains) }\end{array}$ & $\begin{array}{c}\text { Group Four (G4) } \\
\text { (South) }\end{array}$ & $\begin{array}{c}\text { Group Five (G5) } \\
\text { (East) }\end{array}$ \\
\hline $\begin{array}{llll}\text { Arizona } \\
\text { California }\end{array}$ & Michigan & Colorado & Alabama & Delaware \\
Idaho & Minnesota & Illinois & Arkansas & $\begin{array}{l}\text { Indiana } \\
\text { Nevada }\end{array}$ \\
Mow Mexico & New York & Kana & Leorgia & Maryland \\
$\begin{array}{l}\text { Oregon } \\
\text { Utah }\end{array}$ & North Dakota & Missouri & Mississippi & New Jersey \\
Washington & Wouth Dakota & Nebraska & North Carolina & Ohio \\
& Wisconsin & Oklahoma & South Carolina & Pennsylvania \\
& & Texas & Tennessee & Virginia \\
\hline
\end{tabular}


be one where either high or low SDWV diffusion occurred. Since SDWV diffusion was most rapid in Group 1, the West, this region was chosen as the base group.

\section{Results and Discussion}

The results of the static logistic model (7) and the dynamic logistic model (9) are presented in tables 3 and 4, respectively. In both tables, the reported coefficients equal the coefficients from the base group plus the coefficient from the dummy variable for that particular variable in that region. The standard errors and $T$-statistics, however, are for the test that the coefficient for that region is significantly different from the coefficient for the base region (the West). Only the $T$-statistic for the West region is appropriate for determining whether the coefficient is significantly different from zero.

Overall, the dynamic model provides a better fit to the data than the static model. Adjusting

\footnotetext{
${ }^{7}$ Each of the groups act as one unit. The states within each group have fairly homogenous SDWV diffusion rates. Some states within a group may lag behind. But, because of the spillover effect, close locality, and similar market classes of wheat grown, it is assumed SDWV technology was similarly transferred among these states.

In order to check the homogeneity among states within each group each group was run by itself in a cross-section and time-series logistic framework. The base states were Oregon, New York, Oklahoma, South Carolina, and Virginia. With the exception of Kansas, Texas, Indiana, Pennsylvania, North Carolina, and Mississippi, the states, within their respective groups, were not significantly different from the base group. Other groupings were also tested, but only this division gave strong results within and between regions.
}

for additional explanatory variables in the dynamic model increased the $R$-squared measure from 0.46 to 0.67 . In addition, the pattern of diffusion in the two models is quite similar. Considering the coefficients on $N$ and $N^{2}$, both models show similar patterns of signs for the coefficients. In the West and Upper Midwest, increases in the number of cumulative adopters leads to increases in the diffusion rate, although the increases occur at a diminishing rate for larger numbers of cumulative adopters. This deceleration is not observed in any of the other three regions, where both the static and the dynamic diffusion models show a positive coefficient for the $N$ and $N^{2}$ coefficients. However, these positive coefficients for $N^{2}$ for the Plains, the South, and the East may indicate that SDWV have not yet fully diffused in these regions.

Analysis of the value of wheat relative to total farm production in each region substantiates the patterns revealed in the $N$ and $N^{2}$ coefficients. As noted in Griliches (1958), the higher the total value of a crop, the faster the acceptance rate. Wheat has the highest value in the West, the upper Midwest, and the Plains. The South and the East lag behind. This relationship suggests that adoption of SDWVs has progressed most fully in the West and upper Midwest, and less so in the other regions. If true, this result suggests that future empirical analysis of the diffusion of SDWVs in the Plains, South, and East should yield the expected negative coefficient $N^{2}$, as the regions become saturated and increases in land devoted to SDWVs decelerates.

\section{Table 3. Results from Estimating a Static Logistic Using Only the Number of Adopters}

\begin{tabular}{|c|c|c|c|}
\hline Variable & Coefficient & Standard Error & $T$-Statistic \\
\hline \multicolumn{4}{|l|}{ West (G1) } \\
\hline $\bar{N}$ & 0.8204025 & 0.2500690 & 3.280704 \\
\hline$N^{2}$ & -0.007712485 & 0.003044787 & -2.533013 \\
\hline \multicolumn{4}{|c|}{ Upper Midwest (G2) } \\
\hline $\bar{N}$ & 0.4267331 & 0.3326181 & 1.183548 \\
\hline$N^{2}$ & -0.001141102 & -0.005183085 & $\begin{array}{l}1.103340 \\
1.267852\end{array}$ \\
\hline \multicolumn{4}{|l|}{ Plains (G3) } \\
\hline $\bar{N}$ & 0.6785527 & 0.3200809 & 0.4431686 \\
\hline$N^{2}$ & 0.0007691705 & 0.00458963 & 1.848004 \\
\hline \multicolumn{4}{|l|}{ South (G4) } \\
\hline $\bar{N}$ & 0.2359555 & 0.3761646 & 1.5537 \\
\hline$N^{2}$ & 0.00471732 & 0.005530218 & 2.247616 \\
\hline \multicolumn{4}{|l|}{ East (G5) } \\
\hline $\bar{N}$ & 0.1846409 & 0.3420848 & 1.858491 \\
\hline$N^{2}$ & 0.0121731 & 0.00550287 & 3.71505 \\
\hline RBAR**2 & .46 & & \\
\hline$\overline{\mathrm{D} . \mathrm{F} .}$ & 159 & & \\
\hline
\end{tabular}


Table 4. Results from Estimating a Dynamic Logistic Using the Number of Adopters, Prices Received, Prices Paid, and Fertilizer Prices for Five Groups

\begin{tabular}{|c|c|c|c|}
\hline Variable & Coefficient & $\begin{array}{l}\text { Standard } \\
\text { Error }\end{array}$ & $T$-Statistic \\
\hline \multicolumn{4}{|l|}{ West (G1) } \\
\hline $\bar{N}$ & 1.179268 & .2736722 & 4.309052 \\
\hline $\operatorname{Pr}$ & -.09329465 & .05053714 & -1.846061 \\
\hline$P p$ & .05736491 & .06157601 & .9316114 \\
\hline$P f$ & -5.787621 & 2.434321 & -2.377509 \\
\hline$N^{2}$ & -.002765783 & .002829609 & -.9774436 \\
\hline \multicolumn{4}{|c|}{ Upper Midwest (G2) } \\
\hline$N$ & 1.076938 & .3117690 & -.3282208 \\
\hline $\mathrm{Pr}$ & .04508504 & .06622319 & 2.089596 \\
\hline$P p$ & .4549232 & .1012592 & 3.926146 \\
\hline$P f$ & -21.07764 & 3.468241 & -4.408580 \\
\hline$N^{2}$ & -.006138496 & .003294418 & -1.023766 \\
\hline \multicolumn{4}{|l|}{ Plains (G3) } \\
\hline $\bar{N}$ & 1.42598 & 1.301191 & .1896052 \\
\hline $\mathrm{Pr}$ & -.3351066 & .4511594 & -.5359790 \\
\hline$P p$ & .0971373 & .08452221 & .4705556 \\
\hline$P f$ & -1.78292 & 4.063782 & .9854614 \\
\hline$N^{2}$ & .001267546 & .004928605 & .8183510 \\
\hline \multicolumn{4}{|l|}{ South (G4) } \\
\hline $\bar{N}$ & 1.251281 & .3435780 & .2095975 \\
\hline $\mathrm{Pr}$ & -.5080875 & .1913784 & -2.167397 \\
\hline$P p$ & -.1513808 & .09975378 & -2.092610 \\
\hline$P f$ & 9.663808 & 4.728954 & 3.267410 \\
\hline$N^{2}$ & .001882715 & .004080817 & 1.139110 \\
\hline \multicolumn{4}{|l|}{ East (G5) } \\
\hline $\bar{N}$ & .5686835 & .3426880 & 1.781749 \\
\hline$P r$ & -.2944101 & .2310009 & -.8706264 \\
\hline$P p$ & -.01216012 & .1352383 & -.5140929 \\
\hline$P f$ & 4.847369 & 7.445705 & 1.428339 \\
\hline$N^{2}$ & .008456703 & .004070585 & 2.756971 \\
\hline RBAR**2 & .67 & & \\
\hline$\overline{\mathrm{D} . \mathrm{F} .}$ & $144^{.01}$ & & \\
\hline
\end{tabular}

1 States and characteristics of each group are found in tables 1 and 2.

The price coefficients from the dynamic model are less enlightening. In particular, the signs on the coefficients for the prices received $(P r)$ and prices paid for seed $(P p)$ do not follow any clear pattern. There are four potential explanations for this failure. ${ }^{8}$ First, farmers may not be price responsive, at least to these two variables. Second, these price variables may have a significant effect but not in a way that the model estimated here can uncover. For example, prices paid for seed may interact with another variable

\footnotetext{
${ }^{8}$ The dynamic model was run using long-term prices for all three variables (measured by a five-year lagged average). Long-term prices not only gave signs that followed less of a pattern than those obtained in the short-run prices case, but also had lower $t$-statistics. Thus, it is not the use of short-run output prices per se that is responsible for the pattern of coefficients on the price variables. Theoretical justification for the use of one-year lagged prices is presented in Tomek and Robinson.
}

(such as farm income), and through this interactive effect may significantly affect adoption. Finally, coefficient estimates may be confused because of the lack of variation on the $\mathrm{Pr}$ and $P p$ variables. For example, this lack of variation may be attributed in the former case to government programs maintaining artificially high prices for wheat. Fourth, the estimated model suffers from collinearity, since the price variables are all multiplied by $N$, which is also an independent variable in the model. ${ }^{9}$

\footnotetext{
${ }^{9}$ The correlations between $N$ and $N P r$ and between $N$ and $N P p$ were roughly 0.9 . The correlation between $N$ and $N P f$ was slightly less. Although there are techniques to correct for near multicollinearity, such as bayesian mixed estimation and adding data, neither were feasible here (because of the lack of a second data set). Results from models with multicollinearity are unbiased, although inefficient. This implies that multicollinearity cannot account for the switched signs on some of the price variables, although it may account for the small $t$-statistics.
} 
On the other hand, fertilizer prices $(P f)$ have influenced the diffusion of SDWV, particularly in the West, the Upper Midwest, and the Plains (the three high value-of-wheat regions). For these three regions, the sign is correct, indicating that as the price of this input decreases, farmers purchased more SDWV seed. It is not surprising that fertilizer prices have a significant impact on SDWV diffusion. The improved yield capacity of SDWV over standard tall varieties was largely the result of its ability to withstand heavier heads brought about by increased fertilizer applications.

Fertilizer prices appear less important in explaining the behavior of the late-adopting regions of the South and the East. This result is consistent with Cochrane's treadmill theory (Cochrane 1958, 1986). According to Cochrane, as diffusion proceeds, the role of prices may diminish if the higher production dampens prices. While the initial increase in production because of the adoption of a new technology may not be enough to increase total supply, early adopters reap the benefits of new technologies through receiving old prices and increasing output per unit of input. However, middle and late adopters cause supply to increase appreciably. As a result, middle and late adopters do not benefit from an increase in the total value product over an increase in total costs.

\section{Concluding Comments}

This paper has presented a method by which diffusion models can incorporate dynamic factors such as changes in the maximum number of adopters and in the technology and the possibility of disadoption. The approach allows the researcher to avoid the extreme data burdens (in particular, the necessity for cost data) that arise in other dynamic diffusion models. This method was used to estimate the diffusion of semi-dwarf wheat varieties (SDWVs) in the United States from 1959-84. Comparisons with results from a static diffusion model show that the dynamic model provides a better fit to the data as well as offering insights into the economic determinants of adoption.

The results of this paper also indicate the importance of including other innovations that affect the diffusion or development of the innovation being studied. The pattern of adoption of SDWV's was affected to a considerable extent by changes in fertilizer prices, which themselves resulted from technological innovations in the fertilizer industry. Incorporating these complex relationships may be necessary in order to explain satisfactorily the patterns of adoption of technological innovations. For example, a firm trying to market herbicide resistant varieties must consider the price of herbicide and other inputs as well as the management skills needed to assure the prompt adoption of these new varieties. Policy analysts may need to consider how price affects the adoption of new agricultural practices, such as low input agricultural practices.

This point is pertinent to many agricultural process innovations being developed today. Due to the poor prices of the $1980 \mathrm{~s}$, and the current concern over the environment, many agricultural companies are marketing production packages instead of just one input. Hence, they need models, such as the one developed in this paper, that allow for the impact of another innovation.

\section{[Received April 1989; final revision received November 1990.]}

\section{References}

Bass, F. M. "A New Product Growth Model for Consumer Durables." Manag. Sci. 15(1969):215-27.

Bayer, J., and N. Melone. "Predicting Acquisition and Adoption of Software Engineering Innovations." Work. Pap. No 42-86-87, Carnegie-Mellon University, 1987.

Chow, G. C. "Technological Change and the Demand for Computers." Amer. Econ. Rev. 57(1967):1117-30.

Cochrane, W. W. "A New Sheet of Music. How Kennedy's Farm Adviser Has Changed His Tune About Commodity Policy and Why." CHOICES 1(1986):1115.

Farm Prices. Myth and Reality. Minneapolis: University of Minnesota Press, 1958.

Dixon, R. "Hybrid Corn Revisited." Econometrica 48(1980): 1451-61.

Griliches, Z. "Hybrid Corn: An Exploration in the Economics of Technological Change." Econometrica 25(1957):501-22.

—. "Research Costs and Social Returns: Hybrid Corn and Related Innovations." I Polit. Econ. 66(1958):41931.

Knudson, M. K. The Invention and Diffusion of Two Competing Technologies: Semi-Dwarf and Hybrid Wheat. Ph.D. thesis, University of Minnesota, 1988.

Mahajan, V., and R. A. Peterson. "Innovation Diffusion in a Dynamic Potential Adopter Population." Manage. Sci. 24(1978): 1589-97.

- Models for Innovation. Beverly Hills CA: Sage Publications, 1985.

Mansfield, E. "Technical Change and the Rate of Imitation." Econometrica 29(1961):741-66.

Meilke, K. D. "Another Look at the Hog-Corn Ratio." Amer. J. Agr. Econ. 59(1977):216-19. 
Mctcalfe, J. S. "Impulse and Diffusion in the Study of Technical Change." Futures (1981):347-59.

Metcalfe, J. S., and M. Gibbons. "Industrial Policy and the Evolution of Technology." Paper presented at conference, Technological Innovation and Production Structure: The Position of Italy. Milan, Italy, 1983.

Peterson, W. L. "International Farm Prices and the Social Cost of Cheap Food Policies." Amer. J. Agr. Econ. 61(1979):12-21.

Schumpeter, J. The Theory of Economic Development. Cambridge MA: Harvard University Press, 1934.

Stoneman, P. The Economic Analysis of Technological Change. New York: Oxford University Press, 1983.
Timmer, C. P., and W. P. Falcon. "The Political Economy of Rice Production and Trade in Asia." Agriculture in Development Theory, ed. L. G. Reynold, pp. 373-410. New Haven CT: Yale University Press, 1975.

Tomek, W. G., and K. L. Robinson. Agricultural Product Prices. Second Edition. Ithaca: Comell University Press, 1981.

U.S. Department of Agriculture, Economic Research Service. State-Level Wheat Statistics, 1949-1988. Statist. Bull. No. 779. Washington DC, 1989.

White, H. "A Heteroskedasticity-Consistent Covariance Matrix Estimator and Direct Test of Heteroskedasticity." Econometrica 48(1980):817-38. 